\title{
IMPOSIÇÃO DO DIREITO SANITÁRIO SOBRE OS INTERESSES ECONÔMICOS E COMERCIAIS NAS ZONAS PORTUÁRIAS. ANÁLISE DE UM CASO CONCRETO
}

\section{Luís Praxedes Vieira da Silva}

Mestre em Direito (UFC). Professor do curso de Direito da Unifor. Juiz Federal em Fortaleza (CE).

luispraxedes@unifor.br

Sumário: Introdução. 1. Fluxo comercial nas zonas portuárias. Importação e exportação. 2. Superioridade do Direito Sanitário sobre os interesses comerciais nas relações de comércio exterior. Conclusão. Referências.

Resumo: Podem os interesses comerciais superar os interesses de saúde da população de um determinado país? Esta é a indagação feita na análise deste trabalho a partir da ótica de um juiz ao ter que decidir um determinado caso concreto de produto alimentício importado e que foi declarado impróprio para o consumo pela Agência Nacional de Vigilância Sanitária.

Palavras-chave: Comércio exterior. Direito Sanitário. Atuação Judicial. Direito Concreto

\section{INTRODUÇÃO}

As zonas portuárias de qualquer país têm uma grande importância estratégica e comercial. É por intermédio delas que a movimentação econômica mais significativa acontece, através de importação e exportação de mercadorias, já que o grande volume de mercadorias, tanto em quantidade como em dimensões, é transportado hoje em dia através dos navios de grande porte. Principalmente através dos containeres, regulados pela lei 6.288/1975, sem falar no transporte de combustível fóssil, feito pelos grandes navios petroleiros.

As áreas dos portos e aeroportos, por serem estratégicas para o poder público, concentram diversas atividades públicas de controle, como a atividade 
de fiscalização tributária sobre o comércio exterior, conforme previsto no art. 237 da Constituição Federal: “Art. 237. A fiscalização e o controle sobre o comércio exterior, essenciais à defesa dos interesses fazendários nacionais, serão exercidos pelo Ministério da Fazenda."

Temos também as empresas que controlam o armazenamento das mercadorias que chegam do exterior nos navios e das que aguardam a liberação para exportação. E as que fazem um trabalho igualmente importante e estratégico que são as equipes do Ministério da Agricultura para o controle das mercadorias consumíveis que saem e principalmente das que entram, bem como das equipes de vigilância sanitária para o controle de pragas e doenças, tendo um importante poder de polícia administrativo, garantido por lei, para que possam bem desempenhar este relevante serviço público.

$\mathrm{O}$ que fazer quando se constata que uma determinada mercadoria consumível, como arroz, por exemplo, em grande quantidade, está estragada? O que pode fazer o Poder Judiciário quando, em meio à discussão de um processo judicial, que envolve o questionamento de um desembaraço aduaneiro e da declaração judicial de invalidação, de uma decretação da pena de perdimento de mercadoria feita pela Receita Federal Alfandegária, a ANVISA (Agência Nacional de Vigilância Sanitária) constata que a mercadoria está estragada e não pode ser liberada? Dá para se aproveitar a mercadoria? É possível se passar por um processo de transformação para aproveitá-la? Ou a mesma deve ser destruída? Estes são questionamentos que o juiz deve ter em mente ao ter que decidir a causa. Como deverá enfrentar tal situação?

\section{FLUXO COMERCIAL NAS ZONAS PORTUÁRIAS. IMPORTAÇÃO E EXPORTAÇÃO}

Não resta dúvida de que a grandeza e pujança de um país se dá pela sua capacidade de produção interna, pelo crescimento econômico e pelo equilíbrio de sua balança comercial. Ou seja, o país deverá ser capaz de exportar mais e importar menos. Interessante sobre esta proposição o que diz Arthur Schopenhauer sobre a independência pessoal do homem, comparada a de uma nação:

Assim como é venturoso o país que precisa de pouca ou de nenhuma importação, também o é o homem que se satisfaz com a riqueza interior e que, para entreter-se, não necessita de nada, ou de pouco que venha de fora, é que essa importação custa muito, torna dependente, traz perigos, descontenta, e não é, afinal, senão um mal sucedâneo das produções do próprio solo. (SCHOPENHAUER, 1964). 
Mas hoje em dia a concepção é outra. Nenhum país que queira progredir pode prescindir do intenso comércio internacional. A China, isolada na época da Revolução Cultural de Mao Tse Tung nos anos 1960, despontou depois para "economia socialista de mercado" de Deng Xiaoping e é hoje a economia que mais cresce no mundo. Portanto, a globalização é um fenômeno do qual nenhum país que queira crescer pode fugir. mércio exterior.

Por isso, cada país define como estratégica a sua política de co-

Sobre o comércio exterior, torna-se relevante apresentar as seguintes estatísticas sobre o fluxo do comércio exterior em 2006, importações, exportações e balança comercial (ALMANAQUE ABRIL, 2008, p. 99):

\begin{tabular}{|c|c|c|c|}
\hline \multicolumn{4}{|c|}{ EXPORTAÇÕES BRASILEIRAS EM 2006} \\
\hline \multicolumn{2}{|c|}{$\begin{array}{l}\text { PRODUTOS MAIS EXPORTADOS } \\
\text { PELO BRASIL }\end{array}$} & \multicolumn{2}{|c|}{$\begin{array}{l}\text { PRINCIPAIS DESTINOS } \\
\text { DE EXPORTAÇÕES } \\
\text { BRASILEIRAS EM } 2006\end{array}$} \\
\hline PRODUTOS & $\begin{array}{l}\% \text { do valor } \\
\text { exportado }\end{array}$ & PAÍS & $\begin{array}{l}\% \text { do valor } \\
\text { exportado }\end{array}$ \\
\hline Minério de ferro, ferro fundido e aço & 6,51 & EUA & 18,20 \\
\hline Óleos brutos de petróleo & 5,02 & Argentina & 8,60 \\
\hline Soja e derivados & 4,12 & China & 6,40 \\
\hline Automóveis & 3,34 & Alemanha & 4,10 \\
\hline Açúcar de cana, em bruto & 2,86 & Holanda & 4,00 \\
\hline Aviões & 2,36 & México & 3,30 \\
\hline Carne bovina & 2,28 & Chile & 2,90 \\
\hline Café cru em grão & 2,13 & Japão & 2,80 \\
\hline Carne de frango & 2,13 & Itália & 2,80 \\
\hline Transmissores/Receptores & 2,11 & Venezuela & 2,50 \\
\hline Resíduo da extração do óleo de soja & 1,76 & Fed. Russa & 2,30 \\
\hline Calçados & 1,42 & Bélgica & 2,20 \\
\hline Couro & 1,36 & Reino Unido & 2,00 \\
\hline
\end{tabular}

Fonte: Almanaque Abril 2008 


\begin{tabular}{|c|c|c|c|}
\hline \multicolumn{4}{|c|}{ IMPORTAÇÕES BRASILEIRAS EM 2006} \\
\hline \multicolumn{2}{|c|}{$\begin{array}{l}\text { PRODUTOS MAIS IMPORTADOS } \\
\text { PELO BRASIL }\end{array}$} & \multicolumn{2}{|c|}{$\begin{array}{l}\text { PRINCIPAIS ORIGENS } \\
\text { DE IMPORTAÇÕES } \\
\text { BRASILEIRAS EM } 2006\end{array}$} \\
\hline PRODUTOS & $\begin{array}{l}\% \text { do valor } \\
\text { exportado }\end{array}$ & PAÍS & $\begin{array}{l}\% \text { do valor } \\
\text { exportado }\end{array}$ \\
\hline Petróleo bruto & 9,94 & EUA & 16,1 \\
\hline Circuitos eletrônicos & 3,19 & Argentina & 8,6 \\
\hline Peças para veículos & 3,10 & China & 8,4 \\
\hline Transmissores/Receptores & 2,73 & Alemanha & 7,4 \\
\hline Medicamentos & 2,61 & Nigéria & 4,5 \\
\hline Automóveis & 2,09 & Japão & 4,3 \\
\hline Óleos combustíveis & 2,00 & Coreia do Sul & 3,6 \\
\hline Ulhas em pó & 1,63 & Chile & 3,2 \\
\hline Gás natural & 1,44 & França & 3,1 \\
\hline Motores para aviação & 1,39 & Itália & 2,9 \\
\hline Motores para veículos & 1,29 & Argélia & 2,5 \\
\hline Minério de cobre & 1,19 & Taiwan & 1,9 \\
\hline Transformadores/Reatores & 1,13 & Arábia Saudita & 1,8 \\
\hline
\end{tabular}

Fonte: Almanaque Abril 2008

\section{BALANÇA COMERCIAL BRASILEIRA (Em bilhões de dólares)}

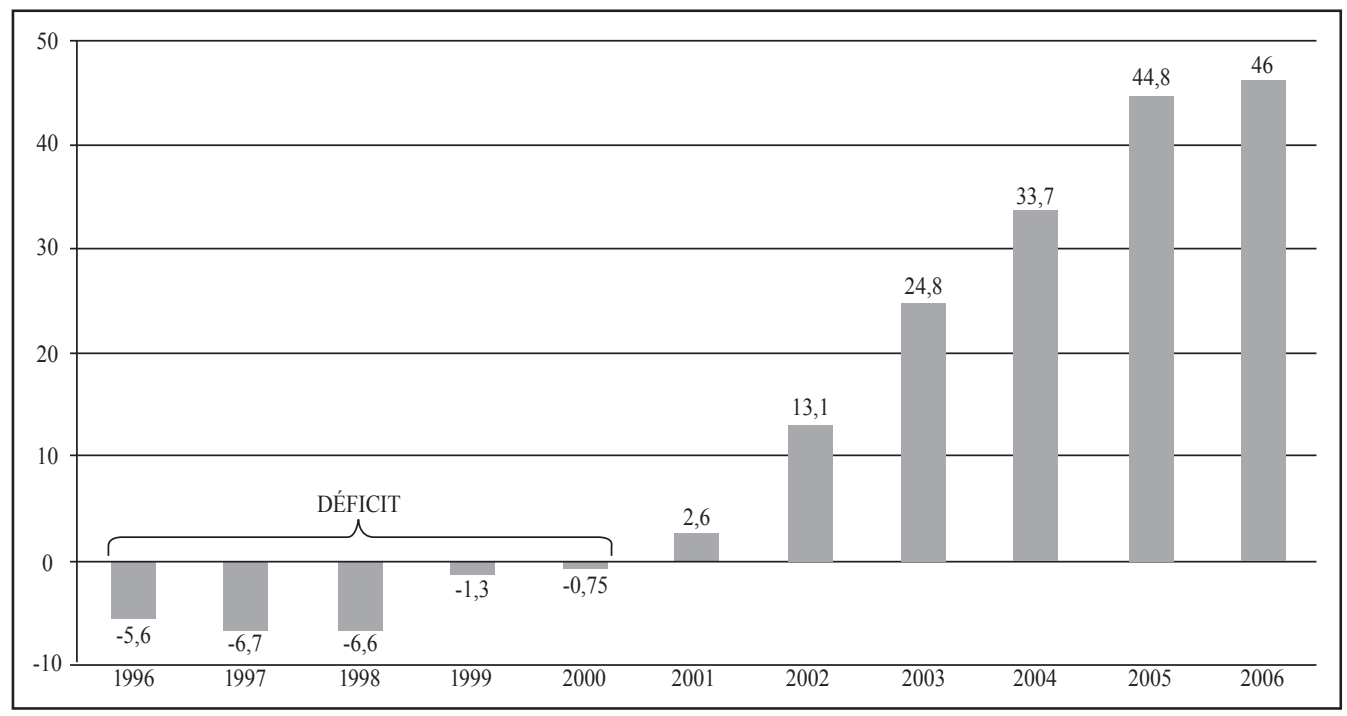

Fonte: Almanaque Abril 2008 
Portanto, a balança comercial brasileira vem apresentando nos últimos anos um superávit comercial, resultado de nossa política voltada para exportações.

\section{Da Superioridade do Direito Sanitário sobre os InTe- Resses Comerciais nas RelaÇões do Comércio ExTerior}

Quando a ANVISA constata a existência de mercadoria deteriorada ou sujeita à contaminação, tem o dever legal de proceder a sua destruição. Estando a questão "sub judice", cabe ao Judiciário endossar a determinação da vigilância sanitária, independente dos prejuízos ou perdas financeiras que tal decisão possa implicar para as partes envolvidas.

Ou seja, a determinação de destruir mercadoria deteriorada na área portuária e de fronteiras é competência legal da ANVISA. As atribuições da Vigilância Sanitária na área portuária estão previstas na Lei $n^{\circ} 6.437 / 1977$, Decreto-lei 986/1969 e Lei 9.782/1999. O direito à saúde da população perpassa toda a Constituição, estando diretamente ligado à proteção da vida, e a vigilância sanitária desempenha papel fundamental neste particular, quando constata, em área portuária, mercadoria estrangeira em avançado estado de deterioração, tendo a ANVISA, no exercício do seu legítimo e legal Poder de Polícia Sanitária que determinar a destruição da mercadoria estragada. Neste sentido têm decidido nossos tribunais:

ADMINISTRATIVO - AUTO DE INFRAÇÃO - ANS - NORMAS SANITÁRIAS - RESPONSABILIDADE DO AGENTE MARÍTIMO - LEI N ${ }^{\circ} 6.437 / 77$ - VERBETE SUMULAR N. 192 DO TRF - INAPLICÁVEL.

I - A ANVISA tem como atribuição institucional a promoção da proteção da saúde da população nacional, por intermédio de fiscalização, inspeção e controle sanitários realizados nos portos, aeroportos e fronteiras do País (art. da Lei 9.782/99). Assim, para tal desiderato institucional, impõe-se a fiscalização e controle sanitário sobre os alimentos ofertados para consumo a bordo de embarcações, bem como os preparados, armazenados, acondicionados dentro do prazo de validade, com vistas a garantir a segurança alimentar e evitar riscos à saúde humana.

II - Os agentes marítimos, na qualidade de representantes dos transportadores, têm a responsabilidade acerca da administração da chegada de embarcações aos portos onde serão fiscalizadas, respondendo perante à Administração Pública por infrações à legislação sanitária, nos termos do art. 10, inc. XXXIII, da Lei $n^{\circ} 6.437 / 77$.

III - Inaplicável o entendimento jurisprudencial cristalizado no verbete $n^{\circ} 192$ do extinto TRF ("O agente marítimo, quando no exercício exclusivo das atribuições próprias, não é considerado responsável tributário, nem se 
equipara ao transportador para efeito do Decreto-lei 37, de 1966”), pois a orientação firmada no mencionado enunciado de súmula diz respeito à questão jurídica regida por normas concernentes ao regime jurídico tributário, o qual contém princípios específicos e regras pontuais destinados à disciplina da relação jurídico-obrigacional tributária. Ao revés, as atuações da ANVISA, em seus misteres de fiscalização sanitária, encontram-se impregnadas de conteúdo discricionário, face à natureza jurídica ostentada pelo ato administrativo fundamentado no Poder de Polícia.

IV - Negado provimento ao apelo. ${ }^{1}$

RESPONSABILIDADE CIVIL. ILEGITIMIDADE ANVISA. ULTILIZAÇÃO INADEQUADA DE MEDICAMENTO.

- Como condição da ação, a legitimidade ad causam pressupõe sempre uma necessária relação entre o sujeito e a causa. No caso, as atribuições cometidas à ANVISA pela Lei n 9.782/99 visam à proteção da saúde da população, por intermédio do controle sanitário da produção e da comercialização de produtos e serviços submetidos à vigilância sanitária, inclusive dos ambientes, dos processos, dos insumos e das tecnologias a eles relacionados, bem como o controle de portos, aeroportos e e fronteiras (art. $6^{\circ}$ ).

- Nesse contexto, se vê que a ANVISA detém nítido poder de polícia, revelado pelo controle e fiscalização dos produtos que podem acarretar danos à saúde pública, dentre os quais se incluem os medicamentos destinados ao consumo humano. A responsabilidade da ANVISA não pode ser ampliada a esse ponto, uma vez que se trata de fato imputado ao fornecedor (por eventual fato do produto) ou de fato de terceiro, pela prescrição e utilização inadequada do medicamento através de médico habilitado.

- Na verdade, não há nexo de causalidade entre a liberação do medicamento pela ANVISA e os prejuizos ocasionados ao agravante. ${ }^{2}$

Os atos da ANVISA exercidos no âmbito de sua atuação é o que Hely Lopes Meirelles denomina de autoexecutório, ou seja, "é aquele que traz em si a possibilidade de ser executado pela própria Administração, independente de ordem judicial" (MEIRELLES, 2000, p. 166). A ANVISA sequer precisaria de ordem judicial para determinar a destruição de produto alimentício destinado ao consumo humano em que foi constatada a sua deterioração. Sobre o assunto, têm decidido nossos tribunais, verbis:

EMENTA: ADMINISTRATIVO-RECURSO ESPECIAL-FECHAMENTO DE PRÉDIO IRREGULAR - AUTOEXECUTORIEDADE DO ATO ADMINISTRATIVO - DESNECESSIDADE DE INVOCAR A TUTELA JUDICIAL.

\footnotetext{
1 (AMS 200351010132246/RJ, Rel. Des. Fed. Theophilo Miguel, TRF 2a Região, Sétima Turma, DJ 21/06/2006, p. 174)

2 (AG 200304010334453/RS, Rela. Des. Fed. Vânia Hack de Almeida, TRF 4 ${ }^{a}$ Região, Terceira Turma, DJ $16 / 04 / 2006$, p. 566)
} 
1. A Administração Pública, pela qualidade do ato administrativo que a permite compelir materialmente o administrado ao seu cumprimento, carece de interesse de procurar as vias judiciais para fazer valer sua vontade, pois pode por seus próprios meios providenciar o fechamento de estabelecimento irregular.

2. Recurso especial improvido.",3

ADMINISTRATIVO. EXPLORAÇÃO DE ÁREA DE PRESERVAÇÃO PERMANENTE. EMBARGOS. AUTO-EXECUTORIEDADE.

1. A ADMINISTRAÇÃO PODE EMBARGAR ATIVIDADES ILEGAIS SEM PROPICIAR PRÉVIA DEFESA AO INFRATOR.

2. A EMPRESA APELADA EXPLOROU ÁREA DE PRESERVAÇÃO PERMANENTE, QUE ESTÁ DENTRO DO PERÍMETRO DE TOMBAMENTO DA SERRA DO MAR E, SENDO INCLUSIVE REINCIDENTE, FICA PERFEITAMENTE CARACTERIZADA A URGENCIA E IRREVERSIBILIDADE DA SITUAÇÃO QUANDO DO EMBARGO.

\section{APELAÇÃO E REMESSA OFICIAL PROVIDAS. "“4}

"EMENTA: ADMINISTRATIVO. AMEAÇA DE TURBAÇÃO EM RODOVIA FEDERAL. EXERCÍCIO DO PODER DE POLÍCIA. AUTOTUTELA. DESNECESSIDADE DE PROVIMENTO JURISDICIONAL. AUSENNCIA DO INTERESSE DE AGIR.

1. A Administração Pública Federal tem o dever-poder de tutelar os seus bens públicos, utilizando-se, para tal finalidade, do exercício dos seus poderes de polícia, ou de autotutela, revestidos de autoexecutoriedade os atos praticados no exercício dessas competências.

2. A ameaça de turbação em rodovias federais pode ser repelida pelas Polícias Federal e Rodoviária Federal, às quais compete a preservação da ordem e do patrimônio públicos. Inteligência dos arts. 144, da CF c/c 27, PARÁGRAFO $7^{\circ}$, da Lei 10.638/2003 c/c art. 20, II e IV, da Lei $n^{\circ}$ 9.503/97.

3. A autoexecutoriedade dos autos praticados no exercício do Poder de Polícia, se faz desnecessária a aprovação, ou chancela, do Poder Judiciário. Ausência do interesse de agir. Sentença mantida. Apelação improvida. "5

Quando os bens são apreendidos ou abandonados na área da aduana a Portaria MF $\mathrm{n}^{\mathrm{o}}$ 100, de 22.04.2002 assim disciplina:

Art. $1^{\circ}$. A destinação dos bens apreendidos, abandonados ou disponiveis, administrados pela Secretaria da Receita Federal, quando não aplicável no art. 29, I, do Decreto-lei $n^{\circ} 1455$, de 07 de abril de 1976, reger-se-á pelas normas estabelecidas nesta portaria.

Art. $2^{\circ}$. Aos bens de que trata esta Portaria poderá ser atribuida uma das seguintes destinações:

\footnotetext{
${ }_{3}^{3}$ (RESP 696993/SP, Rel. Min. Eliana Calmon, STJ, Segunda Turma, DJ 19/12/2005, p. 349)

${ }^{4}$ (AMS 9004200371/PR, Rela. Min. Marga Inge Barth Tessler, TRF 4 ${ }^{a}$ Região, DJ 06/09/1995, p. 58320)

${ }_{5}^{5}$ (AC 329084/PB, Rel. Dês. Fed. Geraldo Apoliano, TRF $5^{\text {a }}$ Região, DJ 26/01/2006, p. 486)
} 


\section{(...)}

V. Destruição ou inutilização nos seguintes casos:

\section{(...)}

c) mercadorias deterioradas, danificadas, estragadas, com data de validade vencida e outras, as quais, de qualquer modo, forem imprestáveis para fins de incorporação ou venda por meio de leilão.

Oportuno ressaltar a importância do Direito Sanitário na atualidade. A normatização promovida pelo Estado constitui-se num ponto fundamental para o fortalecimento do direito sanitário. O Poder de Polícia da Administração Pública possui um elastério de funções, que visa garantir a saúde, o bem comum, $\mathrm{o}$ direito à cidadania $\mathrm{e}$, mais que tudo, o direito à vida.

O saudoso Ruy Cirne Lima já destacava em sua consagrada e pioneira obra, "Princípios de Direito Administrativo", neste sentido:

Polícia Sanitária. Merece especial destaque no Brasil este ramo da Polícia Administrativa. Uma disposição de polícia sanitária teve já, no nosso país, o efeito, real ou protestado, de gerar uma revolução. Trata-se da lei de vacinação obrigatória, a propósito de cuja execução se verificou, a 14 de novembro de 1904, um levante militar chefiado pelo General Lauro Sodré" (LIMA, 1987, p. 118).

Atualmente está em vigor em nosso país a Lei 9.782/1999, que criou o Sistema Nacional de Vigilância Sanitária, atribuindo a responsabilidade de sua manutenção à Agência Nacional de Vigilância Sanitária. Destacamos, assim, os seguintes dispositivos da lei, "verbis:

Art. $2^{\circ}$. Compete à União no âmbito do Sistema de Vigilância Sanitária:

(...)

IV-exercer a vigilância sanitária de portos, aeroportos e fronteiras, podendo essa atribuição ser supletivamente exercida pelos Estados, pelo Distrito Federal e pelos Municípios.

\section{(...)}

Art. $7^{\circ}$. Compete à Agência proceder à implementação e à execução do disposto nos incisos II a VII do art. $2^{\circ}$ desta lei, devendo:

\section{(...)}

$X I V$ - interditar, como medida de vigilância sanitária os locais de fabricação, controle, IMPORTAÇÃO, ARMAZENAMENTO, distribuição e venda de produtos e de prestação de serviços relativos à saúde, em caso de violação da legislação pertinente ou de risco iminente à saúde;

XV - proibir a fabricação, a IMPORTAÇÃO, o ARMAZENAMENTO, a DISTRIBUIÇÃO e a comercialização de produtos e insumos, em caso de violação da legislação pertinente ou de risco iminente à saúde; 


\section{(...)}

Art. $8^{\circ}$. Incumbe à Agência, respeitada a legislação em vigor, regulamentar, controlar e fiscalizar os produtos e serviços que envolvam risco à saúde pública.

$\S 1^{\circ}$. Consideram-se bens e produtos submetidos ao controle e fiscalização sanitária da Agência:

\section{(...)}

II - ALIMENTOS, inclusive bebidas, águas envasadas, seus insumos, suas embalagens, aditivos alimentares, limites de contaminantes orgânicos, resíduos de agrotóxicos e de medicamentos veterinários.

\section{(...)}

$\S 8^{\circ}$. Consideram-se serviços e instalações submetidos ao controle e fiscalização sanitária aqueles relacionados com as atividades de PORTOS, aeroportos e fronteiras e NAS ESTAÇÕES ADUANEIRAS E TERMINAIS ALFANDEGADOS, SERVIÇOS DE TRANSPORTES AQUÁTICOS, TERRESTRES E AÉREOS.” (Letras maiúsculas inseridas pelo expositor)

Sobre a abrangência do Poder de Polícia Sanitária, esclarece o administrativista português Marcello Caetano, definição em tudo coadunada com nossa lei 9.782/1999 que criou a ANVISA, e também com as atribuições do nosso Ministério da Agricultura, neste sentido:

Polícia Sanitária - Desdobra-se a polícia sanitária em três sub-ramos principais: a polícia higiênica, interna e internacional, que previne as doenças endêmicas e epidêmicas; a polícia bromatológica ou da alimentação pública; a polícia médica, que diz respeito ao exercício das diversas profissões que interessam à saúde pública.

\section{(...)}

A policia higienica compreende ainda, na ordem internacional:

- a fiscalização sanitária nas fronteiras terrestres, exercida sobre os viajantes, bagagens e mercadorias, podendo determinar o encerramento da fronteira relativamente ao trânsito de qualquer país onde grasse doença epidêmica.

- o serviço de sanidade marítima, destinado a evitar a importação e exportação de doenças infecciosas por via marítima, e que opera nos portos e nas embarcações, podendo embargar a entrada de navios procedentes de portos infeccionados, exercendo a fiscalização por meio das $<$ visitas de saúde $>$ a bordo, procedendo à desinfecção obrigatória nos casos necessários, atestando por $<$ cartas de saúde $>$ o estado sanitário dos portos de procedência em escala, e inspecionando, em tempos de epidemia, as pessoas que tenham que embarcar.

\section{(...)}

A polícia sanitária da alimentação compete aos médicos sanitários, veterinários municipais e agentes especiais da fiscalização dos gêneros alimentícios.

E compreende: 


\section{(...) \\ - o exame e a análise química, biológica e bacteriológica dos gêneros alimentícios em geral." (CAETANO, 1999, p. 1189/1191)}

Assim, a atuação da Polícia Sanitária nas fronteiras, portos e aeroportos tem uma importância significativa e estratégica para a segurança, economia e saúde de nosso país.

Deve-se levar em conta também que quando se importa mercadoria de outros países é necessário também o controle fitossanitário. Por exemplo, quando se importa arroz da Ásia, continente que apresenta várias pragas que infestam o arroz e muitas que ainda não atingiram ainda a economia nacional, como é o caso do ÁCARO INVASOR, que é a nova ameaça à produção brasileira de arroz, conforme pesquisa feita pela EMBRAPA que pode ser constatada no sítio eletrônico: www.cenargen.embrapa.br. Além do ácaro invasor do arroz (Steneotarsonemus spinki), outras pragas ameaçam o arroz nacional, como a "mancha-parda" e a "brusone". Com ameaças dessa natureza é preciso ter o maior cuidado.

Ora, o cuidado é imprescindível para a segurança, saúde e economia nacional, como é o caso patente da aftosa e mais precisamente da praga do bicudo que simplesmente dizimou a economia nacional e principalmente a cearense na produção de algodão nas décadas de 1980 e 1990, uma praga que ingressou indevidamente em nosso país e liquidou nossa produção local de algodão, que era conhecido como nosso "ouro branco". Só agora, depois de muita pesquisa, é que a EMBRAPA vem selecionando sementes resistentes, mas sem a pujança de antes. Daí a enorme importância da atuação eficiente da Polícia Sanitária em nosso país.

\section{Conclusão}

Inicialmente deve-se ressaltar a importância significativa para a economia nacional do fluxo comercial nas zonas portuárias de nosso país. Por outro lado, o objetivo de obter vantagem econômica encontra limites nos objetivos do Estado Social moderno. Sobre o assunto, adverte o professor Rogério Gesta Leal: "O desafio do Estado Social de Direito é, de alguma forma, garantir justiça social efetiva aos seus cidadãos, no sentido de desenvolvimento da pessoa humana, observando ao mesmo tempo o ordenamento jurídico. Significa dizer que este estado se encontra marcado por preocupações éticas voltadas aos direitos e prerrogativas humanas/fundamentais." (LEAL, 2009, p. 73).

Assim, independente do valor comercial de uma mercadoria consumível importada para o Brasil, ou de sua quantidade, se a mesma apresenta algum problema em sua qualidade de consumo, se tiver estragada, se apresentar a possibilidade de trazer consigo condições de contaminação ou difusão de pragas, 
a mesma deverá ser destruída, desde que constatadas tais situações pela Agência Nacional de Vigilância Sanitária.

Se a questão estiver sub judice, se for possível, estabelecido o devido processo legal, o contraditório e a ampla defesa, garantias constitucionais inseridas no artigo $5^{\circ}$, incisos LIV e LV da Carta da República, o juiz deverá proceder a uma análise pormenorizada do caso, que geralmente envolve a empresa comercial importadora, a Agência Nacional de Vigilância Sanitária e, em alguns casos, a Fazenda Nacional, no caso a Procuradoria da Fazenda Nacional, quando envolver também questões tributárias do comércio exterior. Ressalvados os casos de mandado de segurança, os laudos da ANVISA deverão ser avaliados por uma perícia judicial, se for possível, pois em muitas situações, como já foi ressaltado anteriormente, prevalece o Poder de Polícia Sanitária, envolvido pela autoexecutoriedade dos atos administrativos.

O importante é ressaltar que o Poder Judiciário, no Estado social e democrático de Direito, deve estar preocupado com a saúde e o bem-estar da população, na defesa do ordenamento jurídico e que o argumento econômico imposto pelas leis de mercado, só pode prevalecer quando não ofende os interesses maiores da sociedade.

\section{REFERÊNCIAS}

ALMANAQUE ABRIL 2008. 34. ed. São Paulo: Abril, 2007

CAETANO, Marcello. Manual de Direito Administrativo. Coimbra: Almedina, 1999 GODOY, Arnaldo Sampaio de Moraes. Direito e Economia: introdução ao movimento Law and Economics, Texto extraído do site JUS NAVIGANDI, 19/08/2007, disponível em: http://jus2.uol.com.br/doutrina/texto.asp?id=102555

LEAL, Rogério Gesta. Condições e Possibilidades Eficaciais dos Direitos Fundamentais. Os Desafios do Poder Judiciário no Brasil. Porto Alegre: Livraria do Advogado, 2009

LIMA, Ruy Cirne. Princípios de Direito Administrativo. 6. ed. São Paulo: Revista dos Tribunais, 1987

MEIRELLES, Hely Lopes. Direito Administrativo Brasileiro. São Paulo: Malheiros, 2000

SCHOPENHAUER, Arthur. Aforismos para a Sabedoria na Vida. 4. ed. São Paulo: Melhoramentos 1964

VIANNA, Luiz Werneck, Maria Alice Rezende de Carvalho, Manuel Palácios Cunha Melo, Marcelo Boumann Burgos. A Judicialização da Política e das Relações Sociais no Brasil. Rio de Janeiro: Revan, 1999. 


\section{SANITARY LAW AND ECONOMIC AND COMMERCIAL INTERESTS IN HARBOR ZONES: CASE ANALYSIS}

Abstract: May commercial and economic interests overcome health concerns of a population? This is the main question addressed in this text, under the viewpoint of a federal judge that has to decide a case regarding imported food that was declared improper by Brazil's National Sanitary Agency.

Keywords: International business. Sanitary law. Judicial decision.

Data de recebimento: nov/2010 - Data de aprovação: jan/2011 